\title{
RELAÇÃO DA MANUTENÇÃO PREVENTIVA E CORRETIVA COM INDICADORES DE MANUTENÇÃO
}

Congresso Online de Engenharia de Produção, 7ạ edição, de 07/02/2022 a 10/02/2022

ISBN dos Anais: 978-65-81152-41-3

CONRADO; Silas Maia ${ }^{1}$, ARAÚJO; Danielly Fernandes ${ }^{2}$, JÚNIOR; Madson Fernandes de Melo ${ }^{3}$, VITAL; Luis Filipe Pinheiro ${ }^{4}$, COSTA; Thales Henrique Silva ${ }^{5}$

\section{RESUMO}

Enquanto vantagem competitiva, as empresas estão investindo na manutenção de máquinas e equipamentos, por ser um fator importante para uma indústria, uma vez que, realizada adequadamente, pode evitar quebras e paralisação nas linhas de produção. O objetivo da pesquisa foi avaliar como a manutenção preventiva e corretiva se relaciona com os indicadores de manutenção. O estudo foi realizado numa locadora de máquinas e equipamentos para cozinhas industriais por meio de investigação, utilizando o método dedutivo e descritivo. Quanto à abordagem, utilizou-se o método qualitativo-quantitativo, na avaliação de resultados. Os procedimentos técnicos utilizados foram: documental, expost-facto e estudo de caso. Foram avaliados os 03 equipamentos com quantitativo crítico de manutenção corretiva e preventiva e calculado os indicadores de manutenção MTBF (Tempo Médio Entre Falhas) e MTTR (Tempo Médio de Reparo). Concluiu-se que os dados quantitativos e qualitativos obtidos auxiliaram as atividades de manutenção, prazos de execução, programação das ações do setor de compras de material para manutenção preventiva, além de reduzir o tempo de equipamento e linha de produção parados.

PALAVRAS-CHAVE: Indústria, MTBF, MTTR 